• 论坛・

\title{
“一带一路”与生物遗传资源获取和惠益分享: 关联、路径与策略
}

\author{
李一丁*
}

(贵州大学法学院，贵阳 550025)

\begin{abstract}
摘要: “一带一路”倡议的提出具有重要的时代意义和深远的历史影响。“一带一路”的持续推进和贯彻落实也使得 其发展面向和具体内容日趋多元和丰富。生物遗传资源获取和惠益分享已成为全球生物多样性领域长期、持续关 注的焦点领域和热门话题，其在理念、目标、方式与主体等方面与“一带一路”高度契合。对于中国而言，在“一带 一路”背景下开展生物遗传资源获取和惠益分享应选择双边路径为主、多边路径为辅的方案。未来“一带一路”倡 议下中国与沿线国家开展生物遗传资源获取和惠益分享可能的策略包括: 提出地区或区域性生物遗传资源获取和 惠益分享行动规划, 实施地区或区域性生物遗传资源获取和惠益分享行动倡议, 持续推动国内生物遗传资源获取 管制法律和监管体制创设, 开展生物遗传资源获取和惠益分享能力建设项目。
\end{abstract}

关键词: “一带一路”; 生物遗传资源; 获取和惠益分享; 关联、路径与策略

\section{The Belt and Road initiative and access and benefit-sharing to biological genetic resource: Connection, pathway and strategies}

\author{
Yiding $\mathrm{Li}^{*}$ \\ School of Law, Guizhou University, Guiyang 550025
}

\begin{abstract}
The Belt and Road initiative has significant timely meaning and profound historical influence. As still pushing and make in practice to the initiative mentioned above, the concrete content of the initiative becomes abundant and pluralism. Access and benefit-sharing to biological genetic resource is a focus area and hot issue in the field of biodiversity persistently and long-term that have inter-connection with the initiative of the Belt and Road in ideas, goals, manner and subject. For China, in the background of the Belt and Road, it should be make a choice to two side pathway as principal and multi side pathway as auxiliary. In the future, China may consider to raise the regional or trans-regional initiative of access and benefit-sharing to biological genetic resource and implement it, push and stipulate the legislation and administrative regulate system relates to this issue continuity, and carry out the programe of capability construction enhancement.
\end{abstract}

Key words: the Belt and Road initiative; access and benefit-sharing; biological genetic resource; connection; pathway and the strategies

“一带一路”是新时期中国最富实质内容、最具 明确路径的对外开放经济战略计划, 将有力塑造中 国进一步崛起的地缘经济路径, 打造中国与世界互 联、互通、互动、互赢的新方式, 也将成为中国夯 实全球经济大国地位, 引领新一轮全球化, 建设人 类命运共同体的重要抓手(傅梦孜和徐刚, 2017)。近
年来, 从建设战略规划到愿景与行动, 再到文化(文 化和旅游部, 2016)、中医 药(国家中医药管理局和国 家发展和改革委员会, 2017)、生态环境(环境保护部, 2017)、气象 (http:///www.cma.gov.cn/2011xwzw/2011 xqxxw/2011xqxxw/201801/t20180109_459713.html)、 科技创新合作(科技部等, 2018)等领域发布若干行

收稿日期: 2019-07-16; 接受日期: 2019-10-30

* 通讯作者 Author for correspondence. E-mail: calvin1594@gmail.com 
动规划, 该倡议已经实现了从“口头到书面再到行 动”的转变。随着“一带一路”理念持续推进和贯彻落 实, 其所涉及的面向和内容将趋于多元和丰富。“一 带一路”与生物遗传资源获取和惠益分享具有何种 关联? “一带一路”背景下我国应以何种路径规划、 组织并开展生物遗传资源获取和惠益分享? 依托 “一带一路”倡议我国与沿线国家进行生物遗传资源 获取和惠益分享的发展策略如何? 均是受到关注 的问题。本文拟对此进行分析。

1 “一带一路”与生物遗传资源获取和惠益分享的

“一带一路”不仅是沿线国家所处地理、地域名 称的指代, 更是一种试图打破旧的全球政治经济文 化生态秩序而提出的全新发展理念与需求。《生物 多样性公约》(Convention on Biological Diversity, 以 下简称CBD)、《生物多样性公约关于获取遗传资源 和公正和公平分享其利用所产生惠益的名古屋议 定书》(The Nagoya Protocol on Access to Genetic Resource and the Fair and Equitable Sharing of Benefits Arising from Their Utilization to the Convention on Biological Diversity，以下简称《名古屋议定书》)、 《粮食和农业植物遗传资源国际公约》(International Treaty on Plant Genetic Resource on Food and Agriculture, 以下简称《粮农公约》) 是当前与生物 遗传资源(如无专门提及, 本文生物遗传资源概念 包括生物遗传资源相关传统知识)相关的三项国际 法律文件, 获取和惠益分享不仅是CBD公约设立的 三大目标之一，亦是规范和管理全球生物遗传资源 及相关传统知识的核心法律机制(李一丁, 2016)。生 物遗传资源获取和惠益分享与“一带一路”在理念、 目标、方式、主体等方面具有紧密关联。

\section{1 理念一致}

中国政府推行“一带一路”的理念主要有和平合 作、开放包容、互学互鉴、互利共赢(国家发展和改 革委员会等, 2015), 即共商、共建和共享(王义枚, 2017)。这个三部曲充分凸显了平等理念, 更加符合 人类利益共同体、责任共同体、命运共同体的建设 要求(光明日报2016年7月5日)。而长期以来发达国 家跨国公司打着“生物勘探开发”的旗号, 表面上获 取、开发和利用生物遗传资源, 实际上剽窃当地生 物遗传资源和相关传统知识的行为变相加剧了发
展中国家、欠发达国家等资源来源国、提供国的贫 穷与落后。CBD、《名古屋议定书》、《粮农条约》 创设获取和惠益分享机制的理念就是为了改变这 种“南北失衡”的局面，实现不同国家在生物遗传资 源获取、开发和利用领域的共赢和共享。

\section{2 目标等同}

中国政府推动“一带一路”的目标是试图打造 “政治互信、经济融合、文化包容”的利益共同体、 责任共同体和命运共同体。利益共享、责任共担是 打造命运共同体的重要基础和必由之路, 打造命运 共同体则是构建利益共同体和责任共同体的结合 和升华(肖金明和张晓明, 2017)。通过CBD、《名古 屋议定书》及《粮农条约》提供的获取和惠益分享 基本规则与模式, 明确各参与主体的道德和法律责 任，全球生物遗传资源交易、分配、互换、流转、传 播将实现生物遗传资源提供国和获取国之间的利 益平衡，促成生物遗传资源基础研究价值、商业开 发利用价值的最大化，同时实现生物多样性保护、生 态系统维持这一人与自然界和谐共存的终极目标。

\section{3 方式契合}

中国政府积极利用双边和多边合作机制推动 “一带一路”建设。双边合作机制主要通过与沿线各 国分别签署合作协议、备忘录及合作规划的形式来 建立，多边合作机制主要通过发挥现有国际条约下 的合作机制及国际、区域论坛和协议的形式，这也 说明“一带一路”尊重各国现已存在的合作平台、场 所, 不是另起炉灶或推倒重来, 而是实现战略对 接、优势互补。一直以来, 生物遗传资源获取和惠 益分享议题在世界知识产权组织、粮农组织、联合 国教科文组织、世界卫生组织、世界银行等机构和 组织得到了广泛关注和讨论，这些国际合作机制及 相关机构已然为“一带一路”背景下中国与沿线国家 持续开展生物遗传资源获取和惠益分享提供了合 作基础和平台保障。

\section{4 主体多样}

“一带一路”仅是从地理环境角度对于关联国家 所做的简要区分, 由于其并非完全的闭环，也会引 发各国争相关注和积极加入。此外，除国家以外的 其他主体也会经常参与 “一带一路” 各领域活动或事 务。“一带一路”国际合作还引入了沿线各国企业、 社会组织甚至个人，真正实现了多元主体的共同参 与(秦亚青, 2018)。生物遗传资源获取和惠益分享参 
与主体亦包括获取者(users)、提供者(providers)以及 利益相关者(stakeholders)等。获取者(使用者)多呈现 身份上的差异, 包括企业、公司、高等院校、科研 机构等。生物遗传资源提供者可能范围更广, 主要 有生物遗传资源所在国家、生物遗传资源及相关传 统知识的所有者和持有者等, 而利益相关者则包括 与获取和惠益分享相关的所有主体。

“一带一路”倡议的推广和实施可能给全球范围 内生物遗传资源的获取和惠益分享带来如下影响: (1)参与主体日趋多元。除了沿线国家以外, 跨国公 司、非政府组织、各国获取者、提供者等均能够通 过该倡议加入全球生物遗传资源获取和惠益分享。 (2)适用对象逐渐广泛。“一带一路”倡议将延展获取 和惠益分享的客体, 可知可得的生物遗传资源的种 类、数量、类型不断出现并日益增多。(3)适用范围 逐渐扩展。“一带一路”倡议引领和催生下的生物遗 传资源获取和惠益分享范围将在原全球、区域、本 国生物遗传资源获取和惠益分享的基础上予以扩 展，甚至出现 “一带一路”式生物遗传资源获取和惠 益分享模式。在与“一带一路”倡议相关的绿色发展、 生态环境保护合作两份规划中, 中国也提到要推动 水、大气、土壤、生物多样性等领域的环境保护, 促 进企业主动承担环境社会责任, 严格保护生物多样 性和生态环境(环境保护部等, 2017); 推动生态保 护合作, 推进《生物多样性公约》等履约工作(环境 保护部, 2017)。科技部等四部委联合发布的《推进 “一带一路”建设科技创新合作专项规划》重点领域 中的农业部分、资源部分、医疗健康部分均涉及实 质性的生物遗传资源获取和惠益分享议题，这也说 明一方面“一带一路” 背景下的生物遗传资源获取和 惠益分享已纳入国家战略决策部署, 另一方面也证 实“一带一路”背景下中国与沿线各国开展生物遗传 资源获取和惠益分享具有切实可行性。

\section{2 “一带一路”背景下我国生物遗传资源获取和 益分享的路径}

“一带一路”各国属于世界生物多样性最富集地 区之一, 物种丰富, 生态系统较为完整(陈多闻和张 明, 2017)。从历史视角来看, “一带一路”沿线各国 人民亦具有获取、开发、利用生物遗传资源的历史 和惯例，一方面加快了各地之间物种的互通有无， 另一方面也促进了商品的交易与流转。对于中国而
言，如何在新“一带一路”时期选择既符合本国利 益、又能够确保沿线国家实现生物遗传资源获取、开 发和利用与生物多样性保护、生态系统维持互利共 赢的获取和惠益分享路径, 是一个值得探讨的议题。

\section{1 生物遗传资源获取和惠益分享路径阐释与缺陷}

现阶段全球生物遗传资源获取和惠益分享主 要有双边和多边两种路径。双边路径是指生物遗传 资源获取者、提供者相互之间开展获取和惠益分享 的方式。获取者、提供者通过协商签署书面协议来 实现获取和惠益分享。这种协议与普通民事契约并 非完全一致，它具有双方主体地位不平等、适用对 象并非传统意义上的物或财产、适用范围跨越不同 地域、法域等特征。因参与主体的不同而表现为国 内获取者和提供者以及国内提供者与国外获取者 之间的获取和惠益分享, 这种路径也因获取目的不 同而呈现惠益分享形式和内容的差异。《名古屋议 定书》第十条首次提到全球多边惠益分享机制的问 题，该条款的适用对象为跨境或无法准予或获得事 先知情同意情况下生物遗传资源和相关传统知识 所产生的惠益分享。为了让缔约方更加便捷地获取 粮食和农业植物遗传资源，并在互补和加强的基础 上分享因利用这些资源而产生的惠益，《粮农公约》 建立了高效、透明的多边系统(其本质是一个粮农植 物遗传资源池，见《粮农公约》第十条第二款)。各 缔约方在同时满足给定条件(如该公约第十二条第 三款所设定的若干条件，笔者注)的前提下签署一 份标准材料转让协议、支付对价(《粮农公约》第十 三条)即可获得粮食和农业植物遗传资源。

双边路径一直是CBD、《名古屋议定书》所提 倡和建议的获取和惠益分享方式。但是在“一带一 路”框架下通过双边路径开展获取和惠益分享也面 临不少新问题。比如提供国的增多使得获取国需要 在获取和惠益分享活动前期开展大量的准备工作, 对提供国基本国情、角色身份、获取管制等情况进 行了解认知; 对提供国而言, 除了尽快创设满足本 国生物遗传资源获取管制需求的制度以外，也应针 对自身实际需求不断提高谈判能力并做好谈判商 议准备。

多边路径的本质即为发展中国家主导的区域、 国别生物遗传资源获取和惠益分享多边合作方式, 由于诸多原因一直面临“命运多多”的境地。从《名 古屋议定书》已经召开的两次缔约方大会讨论情况 
来看, 发展中国家和发达国家之间仍存在较大分歧 (徐靖等, 2013), 全球多边惠益分享机制尚未进入到 实质讨论阶段(李一丁和秦天宝, 2018)。《粮农公约》 所推动的多边系统运行情况良好, 如2016-2017年 两年标准材料转让协议的使用数量显著增加, 多边 系统也涵盖了200多万份粮农植物遗传资源样品, 便利超过400多万份样品的国际交换(张小勇和王述 民, 2018)。但是该路径鲜少为发展中国家农民提供 真正的惠益，大部分发展中国家农民的经济收入、 发展水平并未得到根本改善, 进而使得该路径制度 根基不断被侵蚀，实施效果也大打折扣。

\section{2 “一带一路” 背景下路径实践要点与中国方案} 选择

我国既是生物遗传资源传统大国, 又是生物技 术新兴大国, 一直作为生物遗传资源和相关传统知 识提供国存在，近些年来随着国内生物技术产业的 发展也逐渐产生获取需求而成为获取国。中国同时 作为生物遗传资源提供国和获取国出现在“一带一 路”乃至全球生物遗传资源获取和惠益分享场域, 意味着一方面作为提供国, 应极力确保国家及利益 相关方的利益不受减损或将损害风险降至最低, 另 一方面作为获取国, 也应确保并协助其他提供国国 家及其利益相关方实现利益。基于上述身份作用和 角色定位，双边路径既能让中国有序、有效地调整、 约束自身获取和惠益分享行为, 还能借由中国在地 区和区域的公信力、影响力, 带动“一带一路”沿线 国家尽早参与生物遗传资源获取和惠益分享活动。

“一带一路”为双边路径的推进和实施提供了新 的空间和契机，提升并增加了中国与沿线国家生物 遗传资源双边交流合作的机会。“一带一路”背景下 作为获取国的中国应关注以下几个方面的问题：(1) 注重程序正义。不同于有些国家非法获取或不当滥 用行为, 中国应当在CBD、《名古屋议定书》以及“一 带一路”沿线各提供国生物遗传资源和相关传统知 识法律约束下系统、充分和深入履行获取和惠益分 享规则以求实现程序公平公正, 一方面我国获取行 为应事先得到沿线各提供国书面、完全、公开同意; 另一方面获取和惠益分享活动应与沿线各提供国 签署书面协议或文件等等。(2)确保惠益实效。获取 生物遗传资源和相关传统知识后产生的惠益形式 和内容颇具多样化, 但是仍应当依据沿线各提供国 不同国情及需求而进行不同考虑，如构思并设计出
多项惠益分享方案以供参酌。

多边路径的参与和提倡不但能够提升我国在 全球生物遗传资源获取和惠益分享活动中的首位 度，同时也是我国在全球生物多样性领域作为一个 负责任大国积极主动参与全球治理并构建规则的 重要表现(http://www.news.hexun.com/2015-11-04/18 0330116.html)。首先，我国应当在CBD及《名古屋 议定书》缔约方大会以及其他国际舞台、场合继续 团结其他具有相同国情、情势的发展中国家，在“公 共领域”传统知识惠益分享、全球多边惠益共享机 制等议题上表明立场。如在金砖国家峰会论坛上, 中国就提到金砖国家要关注并重视生物遗传资源 获取和惠益分享(中华人民共和国驻新加坡大使馆, 2018)、2017年的“77国+中国”峰会上也呼吁各国应 特别重视海洋生物遗传资源的保护等(http//www. ipsnews.net/2017/03/g77-calls-for-access-benefit-shar ing-of-marine-genetic-resource)。其次，我国亦应考 虑尽快加入《粮农公约》等国际条约。《粮农公约》 提供的是一种与 CBD、《名古屋议定书》迥异的多 边惠益共享机制, 虽然适用对象较为特殊(现阶段 仅适用于《公约》附录1中所列的160余种农作物，笔 者注), 但随着沿线国家不断加入而对我国形成履 约“合围”态势，也给相互间开展粮食和农业植物遗 传资源交流合作带来较大压力。中国在加入后也能 够借由“一带一路”便利与沿线国家开展多边获取和 惠益分享实践。第三，中国亦可考虑推动地区或区 域性多边获取和惠益分享。中国与诸多沿线国家拥 有相似的生态系统和生态环境, 具有共同维护该地 区生态系统平衡、生态环境功能的国际法律义务。 这也给中国提出富有地区和区域特色的生物遗传 资源获取和惠益分享倡议提供现实可能。

“一带一路”背景下我国适宜选择以双边路径为 主、多边路径为辅的获取和惠益分享行动方案。双 边路径不仅具有较为成熟和完整的全球规则规范 体系，国际和国内接受认可程度也较高。我国应在 “一带一路”建设目标、理念引领之下, 在满足自身 需求基础之上与提供国实现利益共享和责任共担。 多边路径正处于蓬勃发展阶段, 中国也面临全新机 遇挑战。这就需要我国持续在各大国际平台、场合 与沿线国家协作发声，尽快考虑加入《粮农公约》 等国际公约, 为多边路径实施运作提供良好示范, 并就地区或区域多边获取和惠益分享创新路径开 
展初步探索。

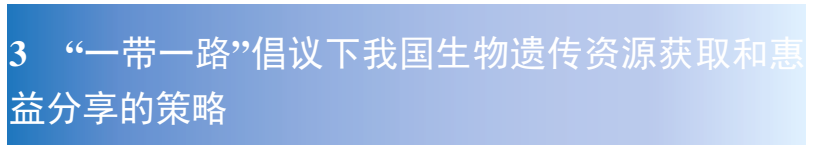

中国已与部分“一带一路”沿线国家开展了生物 遗传资源获取和惠益分享实践, 常见方式是开展科 学研究合作、联合科学考察、继续教育等, 如 2009 年中国科学院西双版纳热带植物园与老挝卫生部 传统药物研究中心签署了长达 5 年的合作协议 (http://www.xtgb.ac.cn/xwzx/zhxw/200901/t20090116_ 2333758.html), 中国科学院昆明植物研究所东南亚 生物多样性中心赴缅甸等国进行植物遗传资源联 合考察(http://www.seabri.cn/scientific-research/fieldsuvey/2018-06-29/351.html), 中国科学院武汉植物 园举办 “一带一路”暨发展中国家科技培训班等 (http://www.whiob.ac.cn/xwdt/zxdt/201810/t20181010_ 5140217.html)。一带一路倡议下中国与沿线国家开 展生物遗传资源获取和惠益分享除了坚持实施双 边路径和提倡多边路径的思路, 还需要在规划、倡 议、法制等方面进行相应的考虑。

\section{1 “一带一路”生物遗传资源和相关传统知识行} 动规划的提出

“一带一路”倡议发展和实施进入了新阶段, 面 临新动向, 目前提出的“一带一路”生物遗传资源和 相关传统知识行动规划契合时宜。该项规划旨在为 中国主导下的“一带一路”生物遗传资源和相关传统 知识获取和惠益分享活动提供基本指导思想、操作 思路、重点领域和路径选择。该项规划包括的内容 主要有: “一带一路”背景下生物遗传资源和相关传 统知识获取和惠益分享的意义与价值; 获取和惠益 分享的路径、特点、适用情形; 获取和惠益分享重 点领域等内容。在该规划中需要依据我国所处情势 对各沿线国家采用不同的策略，如中国作为提供国， 在规划制定过程中应注重对沿线获取国家生物遗 传资源获取和惠益分享进行全过程监测, 以保护和 实现我国国家利益和其他利益相关方利益; 如中国 作为获取国，则应在获取对象、阶段、惠益分享方 式等方面设计不同方案。具体而言, 有的国家不仅 生物遗传资源丰富，且国内政策法制健全，我国应 注重与其 “共商共享”, 在共同商议基础上实现惠益 分享; 有的国家虽然生物遗传资源丰富, 但是国内 政策法制不健全, 我国应注重与其“共商共建”, 通
过与其开展获取和惠益分享，尽可能在提升其惠益 水平的同时提高其对该议题的关注和意识。

\section{2 地区或区域性生物遗传资源获取和惠益分享 行动倡议的实施}

“一带一路”背景下中国提出富有地区和区域特 色的生物遗传资源获取和惠益分享倡议是极具实 践意义的选择。具体而言，中国可联合某些相邻国 家提出如《澜涺流域各国生物遗传资源获取和惠益 分享行动倡议》(暂定名)以及某些学者提到的《青 藏高原地区生物遗传资源获取和惠益分享行动倡 议》(暂定名，尹仑和郑燕燕, 2018)等地区或区域性 行动倡议。这些行动倡议的实施为本地区、区域相 关国家开展生物遗传资源获取和惠益分享合作提 出初步意见和看法，提高沿线国家对生物遗传资源 获取和惠益分享议题的了解和认识，提供平台并尝 试开展双边合作。2018年我国民族植物学界提出的 《“一带一路”生物多样性和传统知识保护昆明宣 言》(http://www.sohu.com/a/241422953_123753)有关 内容可资借鉴。

\section{3 生物遗传资源获取和惠益分享国内法律和监 管体制的持续推动}

现阶段我国已经在农作物种质资源、畜禽遗传 资源、中医药传统知识领域创设获取和惠益分享单 项立法, 也曾经进行过综合性、专门性生物遗传资 源获取管制立法起草尝试，但尚未构建全面、完整 的生物遗传资源获取行政监督管理体制。“一带一 路”对我国生物遗传资源获取和惠益分享国内法律 和行政监管体制的创设完善提出了新的要求，即要 求在我国生物遗传资源获取和惠益分享国内法律 的起草过程中注重国际交流合作，如为加入 《粮农 条约》预留内容和空间等; 还要求我国在构建生物 遗传资源行政监督管理体制过程中要结合《名古屋 议定书》规定考虑如何进行行政资源分配和行政机 构配给，如设置生物遗传资源行政主管当局、检查 点、信息交换所等, 以便为开展双边和多边惠益共 享提供行政保障。

\section{4 生物遗传资源获取和惠益分享能力建设项目} 的开展

生物遗传资源获取和惠益分享实现公平公正 实效的关键在于提高沿线国家对于该问题的意识。 “一带一路”背景下中国应当在获取和惠益分享的全 过程中协助沿线国家提升开展该项活动所需要的 
各种条件。借助中国与沿线国家良好的合作基础, 能力建设活动在主体、方式等方面均可适度延展, 如尽可能地覆盖到沿线国家所有参与主体, 如该国 行政主管部门官员、科学机构研究人员、土著和当 地社区代表; 应尽可能采取多样化能力建设措施, 除了提供进修培训、联合培养高端专业技术人才、 组织开展联合科学考察以外, 亦可共同开展课题研 究并发表研究成果或报告、提供获取和惠益分享技 术协助或指导等。

\section{4 结语}

长期以来, 以发达国家为主导的、以“生物剽 窃” 为表征的全球生物遗传资源获取和惠益分享差 序格局是导致生物遗传资源提供国与获取国之间 利益失衡、矛盾加剧, 发展中国家无法利用或分享 全球生物技术红利进而反复陷入发展困境的深层 次原因。CBD公约、《名古屋议定书》和《粮农公 约》等国际公约、议定书提出的双边路径、多边路 径为改变前述差序格局提供了初步思路与方法, 这 些路径在规则构成、实现目标等方面各不相同, 在 贯彻实施过程中也存在诸多障碍与问题。“一带一 路” 倡议的提出不仅为包括中国在内的多数发展中 国家参与全球生物遗传资源获取和惠益分享活动 提供了全新机遇和平台, 更是将公平、公正、共享 的理念植入全过程及各个环节。基于中国在全球生 物遗传资源获取和惠益分享场域中所具有的双重 身份和角色定位，“一带一路”倡议下中国应当选择 并实施双边路径为主、多边路径为辅的方案以参与 并加入到全球生物遗传资源获取和惠益分享, 助推 中国与沿线国家在生物遗传资源获取、开发和利用 与生物多样性保护、生态系统维持等方面实现互惠 共赢。

\section{参考文献}

Bureau of External Culture Relations, Ministry of Culture, PRC (2016) The Plan of Culture Development of Belt and Road Initiative (2016-2020) (in Chinese) [文化部对外文化 联络局 (2016) 文化部 “一带一路”文化发展计划 (2016-2020)]. http://zwgk.mcprc.org.cn/auto255/201701/t20 170113_477591.html. (accessed on 2018-06-12)

Chen DW, Zhang M (2017) On ecological meaning of the Belt and Road initiative. Qinghai Social Science, (2), 59-62. (in Chinese with English abstract) [陈多闻, 张明 (2017) 论 “一带一路”的生态意蕴. 青海社会科学, (2), 59-62.]
China's Embassy in Singapore (2018) The Declaration of the 10th Meeting of Leaders of BRICs in Johannesburg. (in Chinese) [中华人民共和国驻新加坡共和国大使馆 (2018) 金砖国家领导人第十次会晤约翰内斯堡宣言 (全文)] http://www.mfa.gov.cn/ce/cesg/chn/jrzg/t1580647.html. (accessed on 2019-02-08)

Fu MZ, Xu G (2017) The Belt and Road initiative: Progress, challenge and policy priorities. International Studies, (3), 87-96,126. (in Chinese with English abstract) [傅梦孜, 徐 刚 (2017) “一带一路”: 进展、挑战与应对. 国际问题研 究, (3), 87-96,126.]

Li YD (2016) The research on regime of access and benefitsharing to biological genetic resource and the legal system of intellectual property. Hebei Law Science, 34(1), 51-59. (in Chinese with English abstract) [李一丁 (2016) 论生物 遗传资源获取和惠益分享机制和知识产权制度. 河北法 学, 34(1), 51-59.]

Li YD, Qin TB (2018) Implementation on Nagoya Protocol and the policy and legal preparation in China. Journal of Environmental Protection, 45(23), 23-27. (in Chinese with English abstract) [李一丁, 秦天宝 (2018) 《名古屋议定书》 履约动态分析与国内政策法律准备. 环境保护, 45(23), 23-27.]

Ministry of Environment (2017) The Cooperation Plan of Ecological Environmental Protection of the "Belt and Road" Initiative (in Chinese) [环境保护部 (2017) “一带一路”生 态环境保护合作规划]. http://www.zhb.gov.cn/gkml/hbb/b wj/201705/W20170516330272025970.pdf. (accessed on 20 18-06-12)

Ministry of Environmental Protection, Ministry of Foreign Affairs, National Reform and Development Commission, Ministry of Commerce (2017) Guidance on Promoting the Green Belt and Road Construction (in Chinese) [环境保护 部，外交部，国家发展和改革委员会，商务部 (2017) 关 于推进“一带一路”建设的指导意见]. http://www.zhb.gov. cn/gkml/hbb/bwj/201705/t20170505_413602.html. (accessed on 2018-06-17)

Ministry of Technical and Science, National Reform and Development Commission, Ministry of Foreign Affairs, Ministry of Commerce (2018) Special Plan for Promoting the "Belt and Road” Initiative Construction and Innovation Cooperation (in Chinese) [科技部, 国家发展和改革委员会, 外交 部, 商务部 (2018) 推进“一带一路”建设创新合作专项规 划]. http://www.most.gov.cn/tztg/201609/t201609 14_127689.htm. (accessed on 2019-02-09)

National Administration of Traditional Chinese Medicine, National Development and Reform Commission (2017) The National Reform and Development Commission, Ministry of Foreign Affairs, Ministry of Commerce (2015) Vision and Action on Jointly Building the Road Economic Belt and the 21st Century Maritime Silk Road. (in Chinese) [国 家发展和改革委员会，外交部，商务部 (2015) 推进共 建丝绸之路经济带与 21 世纪海上丝绸之路的愿景与行 
动]. http://www.xinhuanet.com/gaogao/2015-06/08/c_ 127890670.htm. (accessed on 2018-06-17)

Plan of Traditional Chinese Medicine of Belt and Road Initiative (2016-2020). (in Chinese) [国家中医药管理局, 国家 发展和改革委员会 (2017) 中医药 “一带一路”发展规划 (2016-2020)]. http://www.catcm.ac.cn/zykxy/tgaj1/201703/ 1d662e4e4ff246c299c7edbc986b2556.shtml. (accessed on 2018-06-12)

Qin YQ (2018) A newly global governance outlook and the practice of belt and road. Journal of Review of Diplomacy, (12), 1-14. (in Chinese with English abstract) [秦亚青 (2018) 新型全球治理观与 “一带一路” 实践. 外交评论, (12), 1-14.]

Wang YZ (2017) The "Belt and Road" initiatives: A story of Chinese wisdom. Social Science in Chinese Higher Education Institution, (1), 41-51. (in Chinese with English abstract) [王义柧 (2017) “一带一路”的中国智慧. 中国高校 社会科学, (1), 41-51.]

Xiao JM, Zhang XM (2017) The "Belt and Road” initiative and international rule of law: Opportunity, new issues and interaction policy. Theoretical Exploration, (3), 32-37. (in Chinese with English abstract) [肖金明, 张晓明 (2017) “一带 一路”与国际法治: 机遇、新课题与互动之策. 理论探索, (3), 32-37.]

Xu J, Cai L, Wang AH, Xue DY, Yang QW (2013) The global multilateral benefit-sharing mechanism: A new focus in genetic resource access and benefit-sharing negotiations. Biodiversity Science, 21, 127-131. (in Chinese with English abstract) [徐靖, 蔡蕾, 王爱华, 薛达元, 杨庆文 (2013) 全 球多边惠益分享机制：遗传资源获取和惠益分享谈判的 新焦点. 生物多样性, 21, 127-131.]

Yin L, Zheng YY (2018) Developing regional cooperation mechanism on implementing the Convention on Biodiversity among trans-Himalaya under the "Belt and Road" initiative. Journal of Minzu University, China (Nature Science Edition), (4), 65-69. (in Chinese with English abstract) [尹仑, 郑燕燕 (2018) “一带一路”下环喜马拉雅国家履行《生物 多样性公约》合作机制研究. 中央民族大学学报(自然科 学版), (4), 65-69.]

Zhang XY, Wang SM (2018) The implementation progress and reform development on the International Treaty on Plant Genetic Resource for Food and Agriculture: Focus on the multilateral system of access and benefit-sharing. Journal of Plant Genetic Resource, 19, 1019-1029. (in Chinese with English abstract) [张小勇, 王述民 (2018) 《粮食和农业植 物遗传资源国际条约》的实施进展和改革动态一以获 取和惠益分享多边系统为中心. 植物遗传资源学报，19, 1019-1029.]

(责任编委：薛达元 责任编辑：时意专) 